\title{
Decreasing Chinese Cultural Competence Level During COVID-19 and Ways to Better the Situation
}

\author{
Danyi Yu ${ }^{1, *}$, Lujing Rui ${ }^{2}$, Yihan Jia ${ }^{3}$, Yuxin Feng ${ }^{4}$
}

\author{
${ }^{1}$ Viewpoint School, Calabasas 91302, United States \\ ${ }^{2}$ Shanghai Pinghe School, Shanghai 201206, China \\ ${ }^{3}$ Changzhou Senior High School of Jiangsu Province, Changzhou, Jiangsu 213003, China \\ ${ }^{4}$ Chengdu Shude High School, Chengdu, Sichuan 670041, China \\ *Corresponding author. Email: danyiyu36@gmail.com
}

\begin{abstract}
In the following study analyzing the change in Chinese Weibo users' cultural competence before and after exposure to Western responses Chinese media transcribes as Weibo posts, six events were selected with their top 30 most-liked comments categorized according to the code of cultural competence created through sampling previous research. The decrease in the cultural competence of Chinese Weibo users was quantified, and a suggestion of using entertainment, more specifically movies, to deepen the level of cross-cultural skills and competence was subsequently presented. Providing content analysis of the three top-grossing movies in China and qualitatively analyzing the corresponding movie reviews for each film from foreign audiences, our research demonstrates the extent of Chinese cultural competence and evaluates the degree of cultural competence the commentaries possess. With the correlation between movies and the viewers' cultural competence proved by evidence and knowledge of primary reasons for such crosscultural respect and understanding, we proposed the conclusion with several suggestions to improve the decreased level of cultural competence in China during the COVID-19 pandemic.
\end{abstract}

Keywords: Cultural Competence, Weibo, COVID-19

\section{INTRODUCTION}

In recent decades, there have been various studies on cultural competence. Originated from 1989, Cross and his colleagues first defined cultural competence as "a set of congruent behaviors, attitudes, and policies" that combines to create the possibility for all people to "work effectively in cross-cultural situations."[1] The concept of cultural competence developed into an idea applicable to a particular area of studies as Lavizzo-Mourey and Mackenzie redefined it in 1996 as "the demonstrated awareness and integration of three population-specific issues: health-related beliefs and cultural values, disease incidence and prevalence, and treatment efficacy."[1] Betancourt and his colleagues enhanced the same conceptual argument in 2002 by offering a definition solely for the field of health care, describing cultural competences as "the ability of systems to provide care to patients with diverse values, beliefs, and behaviors, including tailoring delivery to meet patients' social, cultural, and linguistic needs."'[1]

Since then, organizations like the American Association for Health Education have applied the concept of cultural competence to help practitioners take care of the patients. These studies all endeavored to explore cultural competence in the field of health care. With a different targeting demographic, our study, instead of trying to safeguard patients, focuses on developing the concept of cultural competence within the context of cultural, civic, and political domains.
Chinese history witnessed the growth of its cultural competence. In 1583, China successfully rejected missionaries from Western Civilizations. Starting from 1840, however, the Opium War, also known as a trade war, opened the gateway to Western invasions of China, both physically and culturally. Western countries, relying on their economic and technological strength, have forced upon China the values and ideologies of their own, threatening cultural traditions and language of China. However, after joining the World Trade Organization in 2001, Chinese sustained rapid economic development has exponentially upgraded the impact of China on an international platform, increasing international cultural communication with other countries to a large extent.

During the Covid-19 global pandemic, the importance of media in the life of the general public soars as people rely on online news sources for new information pertaining to their safety, freedom, and connection with their country as well as the rest of the world. Analysis of several influential events during the Covid-19 global pandemic confirms that the lack of cultural competence plays a significant role in affecting people's attitudes towards particular events. However, this declining trend of cultural competence shown by the news reports during the pandemic could be bettered by the utilization of entertainment.

In 2012, Satish Pandey conducted an exploratory study based on qualitative analysis of the reflection notes of 14 students who participated in an elective course on "managing cross-cultural issues (MCCI)" in the second year of their MBA program. He claims that "popular movies, if appropriately selected and included in crosscultural training programs... could be very useful as a 
learning tool for developing multicultural perspective and cross-cultural competence."'[2] Inspired by this study, it is believed that popular films offer a practical way to increase cultural competence leading to deeper understanding and harmonious relationships across all nations.

As an increasing number of Chinese productions were brought to other countries across the world, Chinese technological advancement and its cultural recognition and communication spurred different opinions. By analyzing movies released after 2017, a conclusion can be drawn that those movies not only transmit Chinese traditional elements and values but also show a trend of coexistence of multiple cultures.

Through conducting research on the application of cultural competence to a different domain accompanied by offering the possible solution to the issue of prevalent cultural incompetence, the usage of films, our study could be influential in spurring new aspects of ways to improve international cooperation and eliminate discriminations.

\section{METHODOLOGY}

With the hypothesis of a cause and effect relationship between entertainment and the degree of cultural competence people possess, this research analyzes the comments under Weibo for existing cultural competence level of the Chinese netizens during the pandemic and investigates the top-grossing movies and their presentation of cultural competence in comparison the status shown in the commentaries of audience.

To evaluate the degree of cultural competence before and after the pandemic from garnered comments of individual netizens, we employed the operationalization method to create a code of cultural competence based on existing research and definitions $[1,3,4]$.

The standard includes the ability to (a) openly discuss differences between one's own culture and another, (b) acknowledge other worldviews (coming from a different culture), (c) behave or talk respectfully with the willingness to build understanding with people of other cultures, (d) actively seek more knowledge regarding other cultures, (e) understand one's own culture, (f) refrain from adhering to stereotypical images of an ethnicity or a race, (g) remain open to change, (h) value diversity, and (i) criticize cultural incompetence.

The code is applied to categorize different comments, actions, words, as well as sentiment shown in the comments under reports, reviews of each movie, and the movie content.

The following six events were chosen for their controversial and influential nature in both Western and Chinese media:

1. Chinese Government Supplying Medical Gears to Other Countries

2. Lockdown of Chinese Cities

3. Naming of COVID-19

4. Conspiracy About the Origin of the Virus From Laboratory
5. Incidents Surrounding Zhang WeiLi

6. Imprints From Goggles On Medical Workers' Faces

To measure the change in the level of cultural competence, thirty comments under the original Chinese reports on the event and thirty under reports of Western responses to the event were selected separately and ranked by likes, indicating agreeableness from other netizens. Then, data is categorized using a modified code including (a) straightforward patriotism with no explanations or comparisons, (b) patriotism with reasonings, (c) arguments based on mutual understanding and rational analysis, (d) insults or mockery against Americans or America, (e) insults or mockery against an individual, and (f) random or non-essential comments.

The assessment standard was generated based on visible qualities of cultural competence and incompetence. Patriotism and rational arguments are evaluated as cultural competence as they demonstrate respect for one's own culture and understanding of one's own or the other culture, and all insults and mockeries are categorized as lack of cultural competence as they lack acceptance and present vulgar qualities.

Three films, Wolf Warrior 2 (2017), Ne Zha (2019), and The Wandering Earth (2019), were chosen according to the ranking of the highest-grossing movies in Chinese history to prove the effects of movies with elements of cultural competence have on their audience[5]. The content analysis of the plot, details, and characters of each film according to our code of cultural competence, as presented in the methodology section, helps deduce the specific elements of cultural competence and, potentially, the areas lacking cultural competence in each movie. The IMDb platform was used to gather primary information of all three films, including the ratings and the overall review. Qualitative analysis is then done to the top ten mosthelpful reviews made by foreigners (non-Chinese), a measure equivalent to agreeableness, concerning different aspects of the commentaries according to our code. All ten comments were grouped into four different categories: Complete Cultural Competence, Show More Cultural Competence, Show More Cultural Incompetence, and Complete Cultural Incompetence. The "show more cultural competence" and "show more cultural incompetence" are measured by evaluating the components that fulfill the code of cultural competence and those that violate it and comparing the quantity of the two. Through statistics, this research can justify the correlation between movies displaying cultural competence and the cultural competence of the audience from another culture. 


\section{RESULTS}

\subsection{Analysis of comments by Chinese Weibo users during COVID-19 pandemic}

\subsubsection{Chinese supplies}

The first event chosen is the reports on the Chinese government supplying other countries with medical and

Comments Under Reports on Chinese Supplies to Other Countries

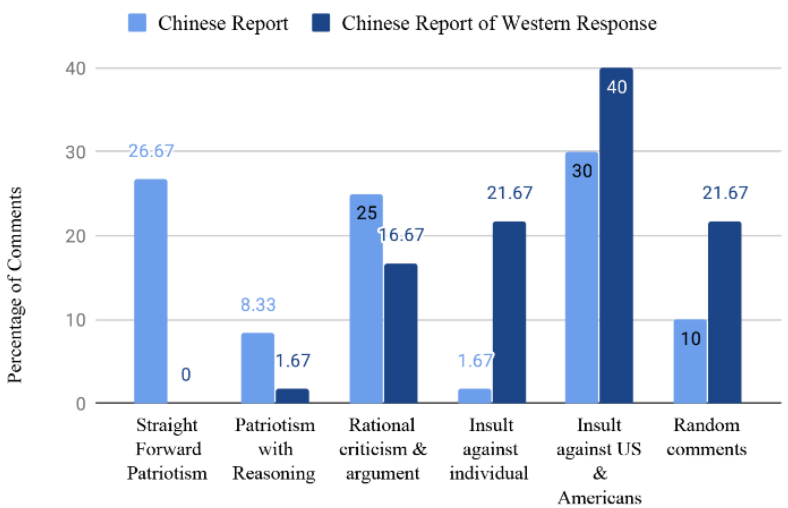

protective gear to combat the COVID-19 pandemic. The original Chinese report states that China has not and will not set any limits in exporting pandemic-related supplies to all foreign countries while the latter report mentions that the Chinese supplies have successfully arrived in Illinois, whose state government has kept the transportation as a secret from the federal government.

Figure. 1 shows the fluctuation of the percentage of comments in different categories classified in the methodology section, as well as the percentage of likes each comment category gets cumulatively.

Likes for Comments Under Reports on Chinese Supplies to Other Countries

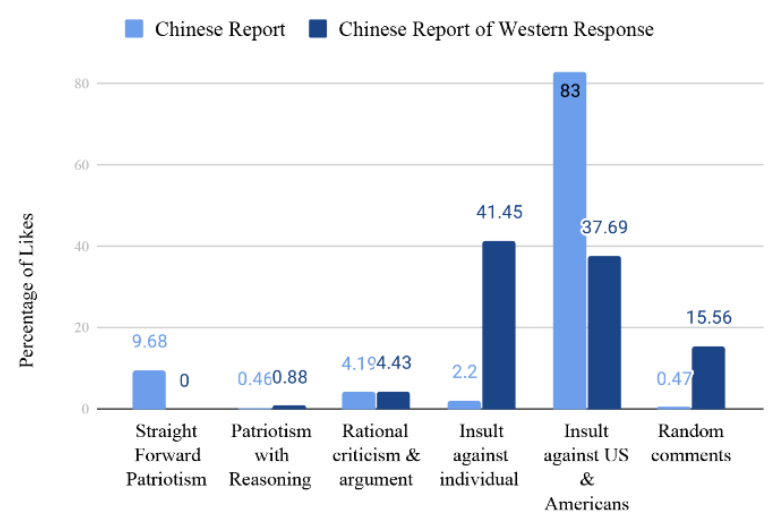

Figure 1. Comparison of Cultural Competence Standard for Comments Under Reports on Chinese Supplies to Other Countries.

As illustrated in Fig. 1, there are both a noticeable increase from $1.67 \%$ to $21.67 \%$ in the number of insults against an individual and an increase from $30 \%$ to $40 \%$ in the percentage of insults against the United States and Americans. In addition, the most liked category of comments alters from insult against the United States and the Americans at $83 \%$ to insult against an individual at $41.45 \%$. This shift in the subject of insults is largely influenced by the wording of the news implying the distrust the state government has for the trump. Both of the statistics combined reveal the growing cultural incompetence with disrespect towards other individuals of other cultures or a generalized group as a whole. Simultaneously, a significant decrease in patriotic statements with straightforward patriotism lowering from $26.67 \%$ to $0 \%$ and patriotism with reasoning from $8.33 \%$ to only $1.67 \%$ was presented. The change signifies the decrease in cultural competence from another perspective: it shows a decreasing trend of expressing confidence in and understanding of one's own culture. The percentage of rational criticism also decreases in its overall component of all comments from $25 \%$ to $16.67 \%$.

\subsubsection{Lockdown of Wuhan}

The second selected event is the lockdown of Wuhan, followed by other cities in China. The original Chinese reports documented the first day of lockdown in the city of Wuhan, and the report on the Western response, on the other hand, contrasts the difference between New York Times' judgemental attitude towards Chinese cities' lockdown and appreciative tone towards Italy's lockdown. The change in the distribution of comments is recorded below in Figure 2. 
Comments Under Reports on Chinese Cities Lockdown

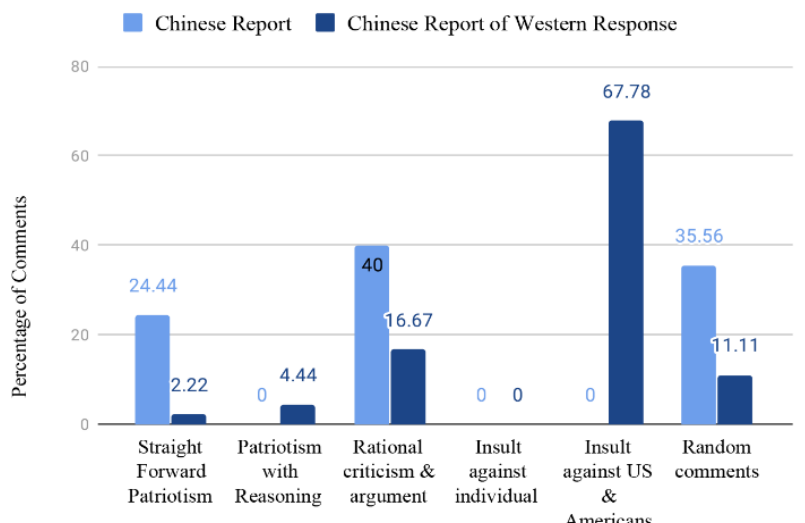

Likes For Comments Under Reports on Chinese Cities Lockdown

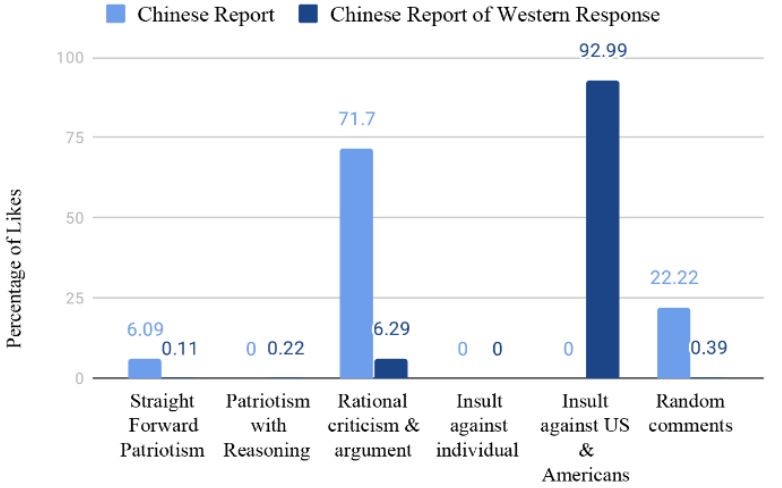

Figure 2. Comparison of Cultural Competence Standard for Comments Under Reports on Chinese Cities Lockdown

As shown in Figure. 2, the proportion of insults against the United States and Americans has increased from nothing to $67.78 \%$. Supplementing it is a decrease in percentages of straightforward patriotism from $24.44 \%$ to $2.22 \%$. The shift in the most liked category of comment from "rational criticism" to "insult against US \& Americans" with the former being $71.7 \%$ and the latter an astonishing $92.99 \%$ indicates a definite change in the attitude of Weibo netizens. Despite the slight increase of $4.44 \%$ in patriotism with reasoning, the general trend demonstrates a decline in the level of cultural competence. The number of rational criticism has also decreased by more than half from $40 \%$ to $16.67 \%$.

Comments Under Reports on Naming of COVID-19

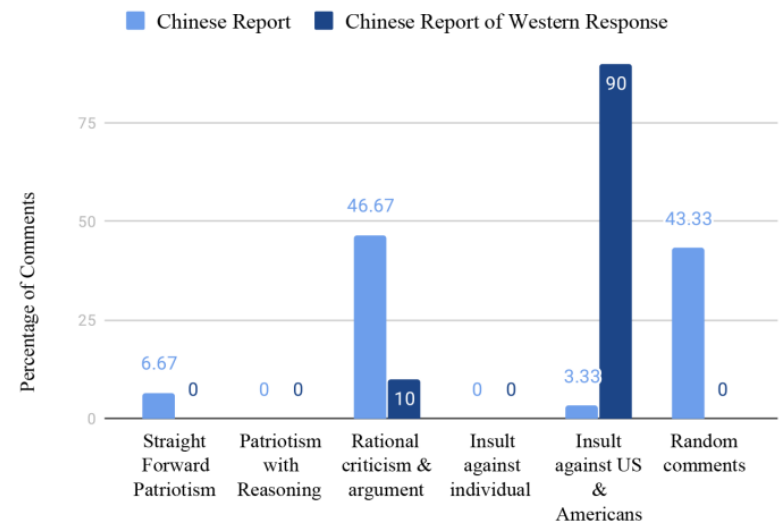

\subsubsection{Naming of the virus}

The next event evaluated is the naming of the coronavirus. The former news posted by the World Health Organization declared the name of the pandemic to be COVID-19 while the latter mentioned that Trump, the president of the U.S., referred to the coronavirus as a Chinese virus.

As shown in Fig. 3, Weibo users' attitudes toward the naming of coronavirus dramatically shifted to an extreme level, which largely shows their cultural incompetence.

Likes For Comments Under Reports on Naming of COVID19

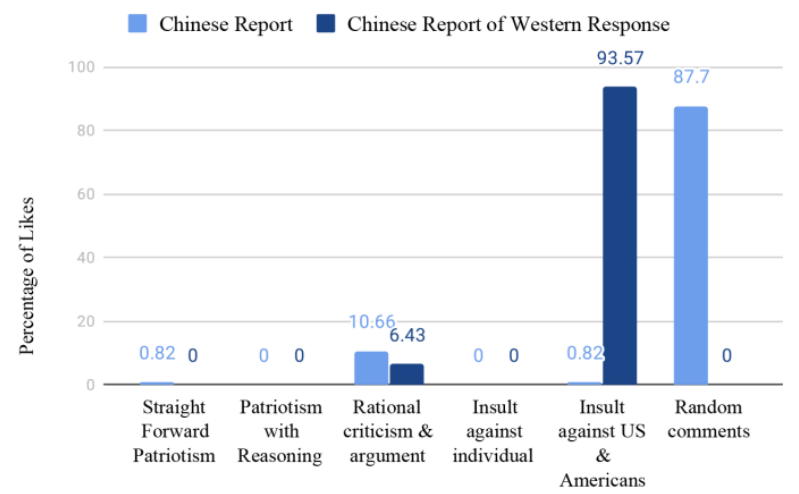

Figure 3. Comparison of Cultural Competence Standard for Comments Under Reports on Naming of COVID-19.

The statistics above reveal that a majority of people changed their attitudes about the naming of coronavirus after Trump's interference, and the proportion of people who displayed insult against US \& Americans had increased from $3.33 \%$ to $90 \%$ while, before, a majority of netizens' comments showed rational criticism \& argument. Furthermore, the shift in "likes" of comment from "patriotism" to "insult against US \& Americans" with the former being $10.66 \%$ and the latter an astonishing $93.57 \%$ showed a dramatic change in the attitude of Weibo netizens.

Even though it was Trump's extreme political tendency that made Weibo users annoyed, insulting words as shown by comments revealed Chinese netizens' cultural incompetence, which refers to the inability of filtering untrue words with strong political inclination. Also, Weibo 
users did not "take actions indicating respect and willingness to build understanding with other people of different cultures," demonstrating Weibo users' cultural incompetence.

\subsubsection{Conspiracy about coronavirus}

The next event chosen is the conspiracy about the origin of coronavirus. The original Chinese report is about Chinese

Comments Under Reports on Conspiracy About the Origin of the Virus

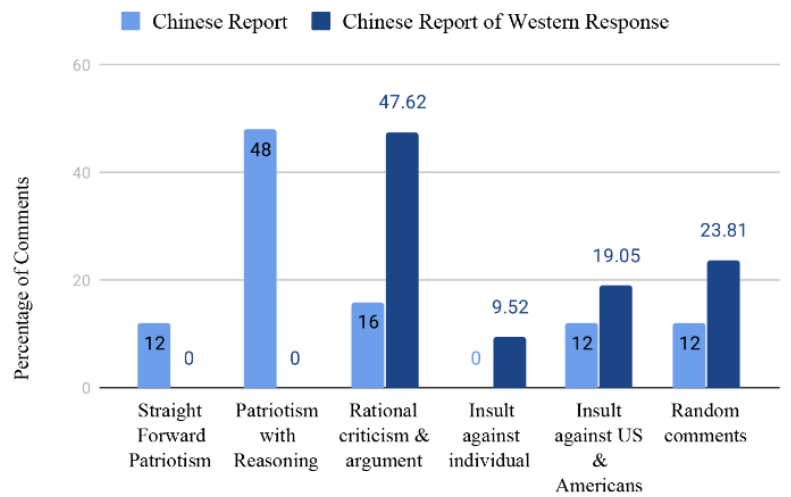

experts' response to the conspiracy theory, claiming that the coronavirus has nothing to do with Chinese laboratories, even betting their life on it; the latter one reports the response from a western media, pointing out several convincing pieces of evidence that the coronavirus could not have been created from a lab.

Likes For Comments Under Reports on Conspiracy About the Origin of the Virus

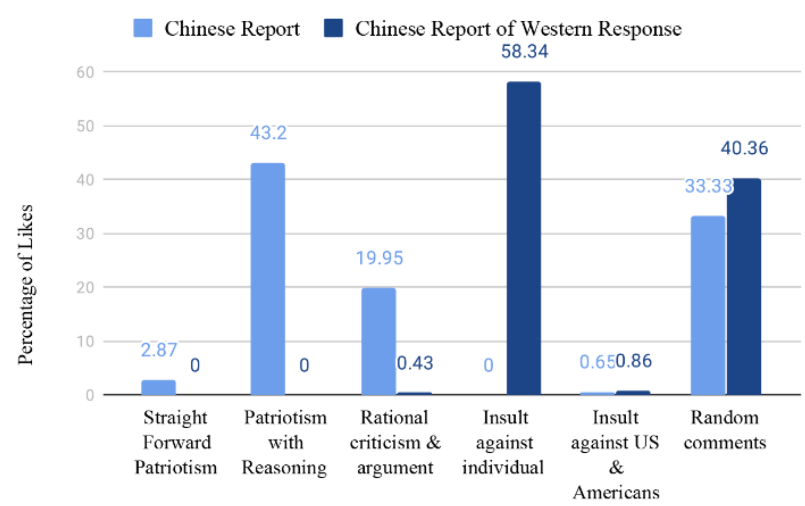

Figure 4. Comparison of Cultural Competence Standard for Comments Under Reports on the Conspiracy About the Origin of the Virus.

As illustrated in Fig. 4, there is a noticeable increase from $16 \%$ to $47.62 \%$ in the number of rational criticism and argument, the kind of comments that usually greatly reduce after Chinese reports of western response with extreme emotional responses from Chinese netizens. The content of the article, however, can explain this exception. It features a western media called Pacific Dialogue, demystifying the conspiracy theory that the virus originated in a Chinese lab. With the perception of information received as the truth, Chinese netizens were more willing to consider this event from a rational and objective point of view. The overwhelming increase in the number of likes for rational and reasonable arguments also confirms this conclusion. However, the proportion of people who display insults against individuals, the US, and Americans still increased from $12 \%$ to $19.5 \%$. There is even a significant increase from almost $0 \%$ to $58.34 \%$ in the percentage of likes for the insult words against Trump and other American government officials. This statistic indicates that even though the post expresses an objective truth, Weibo users are still inclined to make derogatory comments or support those insult words, which alludes to the intractable cultural incompetence many Chinese netizens unconsciously hold.

\subsubsection{Zhang Weili}

The fifth event selected is about a Chinese female boxer, Zhang Weili, the UFC global champion. Arguments arose because of her opponent Joanna, who tried to insult Zhang Weili by posting a decorated poster with herself standing next to Zhang with a gas mask before the match began. The original Chinese report announces that Zhang successfully defended her position as the UFC champion from Joanna and reports her speech about the difficulties Chinese were going through, calling people all around the world to unite against the virus. The latter one is about the news that Zhang Weili's opponent Joanna decides to receive plastic surgery in order to recover from the fight and anticipates another competition with Zhang Weili. 
Comments Under Reports on Zhang WeiLi

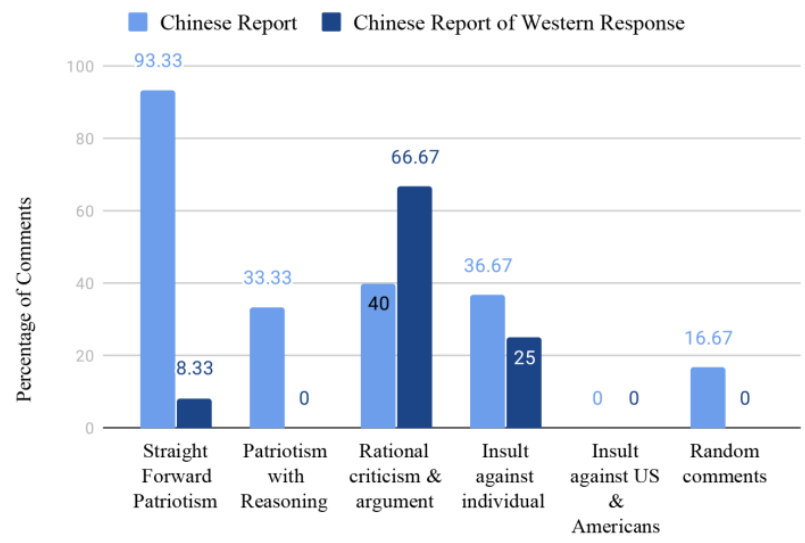

Likes For Comments Under Reports on Zhang WeiLi

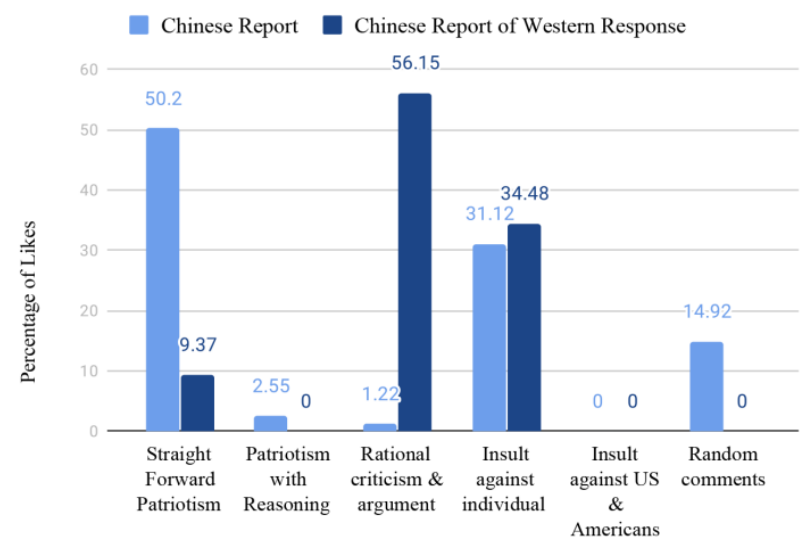

Figure 5. Comparison of Cultural Competence Standard for Comments Under Reports on Zhang Weili.

The statistics above reveal a significant increase from $40 \%$ to $66.67 \%$ in rational criticism and argument and an overwhelming increase in the number of likes for these comments, which is also an abnormal phenomenon compared with the situations of other events selected. After careful observations, it is found that part of the reason accounting for this exception is some comments saying that Joanna has already formally apologized for her improper joke on social media. Besides, many netizens point out that this kind of pre-fight provocation is the typical method used by UFC to attract more attention to maximize commercial profit. Chinese people, as a population advocating modesty and gentility in competitions, face more difficulties in understanding the values from a different culture. With these two awarenesses in mind, Chinese netizens show a relatively higher cultural competence in their comments.

Comments Under Reports on Medical Worker's Imprints

Chinese Report Chinese Report of Western Response

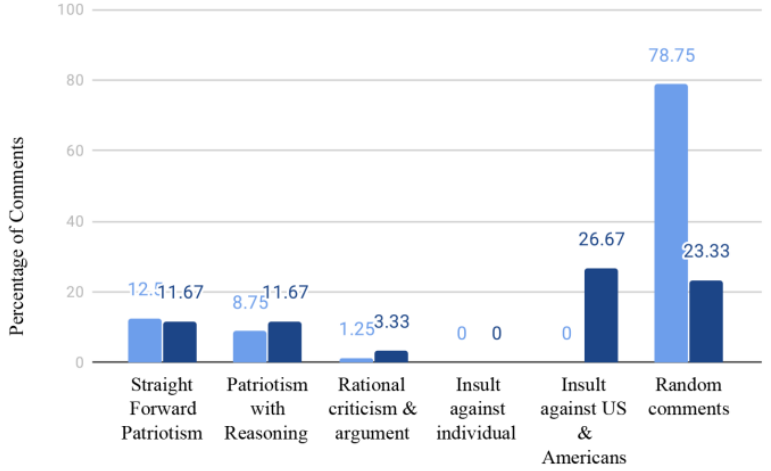

Nevertheless, even though there is a small decrease in the percentage of insults against Joanna, the increase in the number of likes for insult words still indicates a certain degree of cultural incompetence of Weibo users.

\subsubsection{Imprints of goggles on medical workers}

The last event analyzed focuses on medical workers who work nonstop for patients in the hospital. The Chinese report displaying a series of photos showing medical workers' faces with deep imprints from wearing the goggles and masks tightly praised their spirits. However, arguments arose after exposure of netizens to foreigners' responses.

Likes For Comments Under Reports on Medical Worker's Imprints

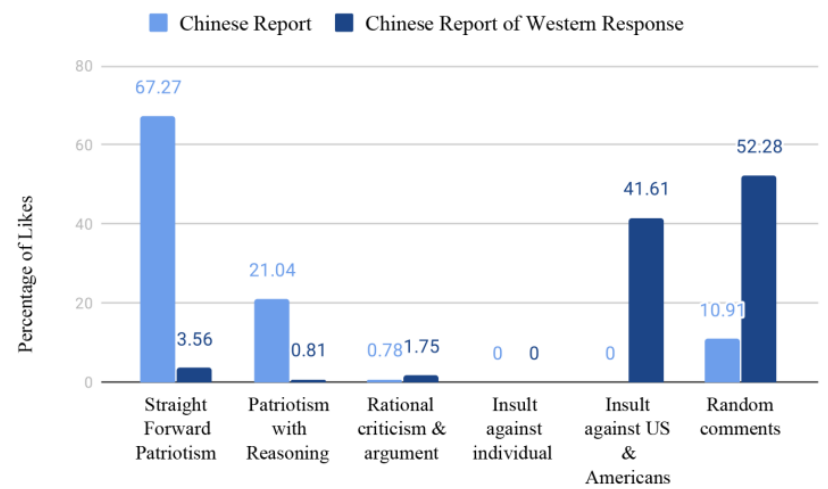

Figure 6. Comparison of Cultural Competence Standard for Comments Under Reports on Imprints of Goggles on Medical Workers.

The above statistics unravel that although the proportion of straightforward patriotism under the Chinese report is only $12.5 \%$, it is able to receive about $67.27 \%$ of likes. Comparatively, while $8.75 \%$ of commentaries signal patriotism with reasoning, they only hold $21.04 \%$ of likes. On the contrary, under the Chinese report of Western response, only $11.67 \%$ of comments are straightforward patriotism with $3.56 \%$ of likes. There are $26.67 \%$ of 
comments directly insulting against the US or Americans, receiving $41.61 \%$ of likes.

For the six events selected, the comments on Weibo under posts created by Chinese media reporting the original incident and posts Chinese media accounts generated of Western responses to the events display an overall increase in the percentage of insult against either an individual or the Americans and the United States, which violates the code of cultural competence, showing an increase in lack of cultural competence.

\subsection{Movies showing cultural competence and comments regarding these movies from IMDb}

\subsubsection{WOLF WARRIOR 2 (2017)}

Wolf Warrior 2 is a 2017 Chinese action film directed by Wu Jing, who also starred as the lead role in the film costarring Celina Jade, Frank Grillo, Hans Zhang, and Wu Gang. As a sequel to Wolf Warrior (2015), the film tells a story of Leng Feng, a Chinese soldier who takes on special missions around the world. In this sequel, he finds himself in an African country protecting medical aid workers from local rebels and vicious arms dealers [6]. Released on October 15, 2017, it became a big hit in China with a cumulative box office of 5 billion yuan. Wolf Warrior 2 was also officially available in the United States, the United Kingdom, Germany, Austria, and other countries. Wolf Warrior 2 received numerous praises for its representation of Chinese patriotism, usage of special effects, well-choreographed action scenes, and the performances of the casts in general. It was a massive commercial success and has become the highest-grossing Chinese film ever released [5]. However, internationally, the film endured mixed responses. Cultural competence, as one of the key reasons for this difference, is shown in Wolf Warrior 2 in the following representative aspects.

First of all, cultural competence is noticeable in the scene with LengFeng competing drinking with an African. In Chinese culture, drinking alcohol is considered an essential way of socializing. People used to believe that boozing can narrow the distance between individuals. Negotiation for agreements and deal-makings are both popular applications of such behavior. In this scene, Leng Feng competes drinking with an African man, both

Table 1. Degree of Cultural Competence in Foreign Commentaries of Wolf Warrior 2 downing Chinese liquor near the end of their competition. This specific display suggests the acceptance and reverence the local population possesses for Chinese culture.

Secondly, Leng Feng decides to protect not only Chinese workers but also the African workers in the factory, while his mission is only to transfer overseas Chinese to secure shelters. With his evaluation of the African workers as equals and thus should not be left behind, the film explicates the inclusiveness of other cultures, an element essential in developing cultural competence.

At last, the themes of this movie include sympathy and protecting the weak: Leng saves the helpless people and sympathizes with Africans. There are many foreign actors in this film, and their actions serve to show cultural competence. When attempting to create conflicts, Wolf Warrior 2 focuses on highlighting internationally recognized values. For example, in the face of danger, women and children should be protected first, and terrorist forces should be resolutely fought to maintain peace and equality. The film utilizes the world's "discourse system" to tell Chinese stories, adding chips to the spread of crosscultural transmission.

However, the cumulative box office from countries outside of China only accounted for $0.3 \%$ of the film's total box office. The result was suspected to correlate directly with nonnatives' misinterpretations of the movies. For example, the use of the word "offend" in China had caused several foreign audiences to mistake China as a powerful sweeping force, although the movie solely wanted to manifest patriotism.

"Once a Wolf Warrior, always a Wolf Warrior" is another classic line in the film. It serves to express Lengfeng's sentiments towards his identity as a member of the Chinese special force as well as his sense of responsibility for the mission of the Chinese soldiers. However, the statement is often interpreted by foreigners as Chinese dogma with overtly political slogans mainly because they lacked the Chinese cultural context for which the movie did not show.

Top ten reviews were picked from the commentaries for Wolf Warrior 2 (2017) on IMDb ranked by helpfulness, a measurement of agreeableness, and analyzed for the level of cultural competence each review possesses using the code of cultural competence. The result is as shown in Table 1.

\begin{tabular}{|c|c|c|c|}
\hline & $\begin{array}{l}\text { Number of } \\
\text { comments }\end{array}$ & $\begin{array}{l}\text { Elements of cultural } \\
\text { competence }\end{array}$ & Elements of cultural incompetence \\
\hline $\begin{array}{l}\text { Complete cultural } \\
\text { incompetence }\end{array}$ & 2 & \multirow{2}{*}{$\begin{array}{l}\text { 1. Common sentiment } \\
\text { shared by all people } \\
\text { 2. Appreciation for } \\
\text { diversity } \\
\text { 3. Respectful of other }\end{array}$} & \multirow{2}{*}{$\begin{array}{l}\text { 1. Disrespectful of other views } \\
\text { 2. Dislike the nationalism } \\
\text { 3. Unwilling to accept other } \\
\text { views } \\
\text { 4. Classification \& }\end{array}$} \\
\hline $\begin{array}{l}\text { Show more cultural } \\
\text { incompetence }\end{array}$ & 2 & & \\
\hline
\end{tabular}




\begin{tabular}{|c|c|c|c|c|c|}
\hline $\begin{array}{l}\text { Show more cultural } \\
\text { competence }\end{array}$ & 2 & \multirow{3}{*}{\multicolumn{2}{|c|}{$\begin{array}{l}\text { 4. Criticism of cultural } \\
\text { incompetence } \\
\text { 5. Appreciation for good } \\
\text { Chinese production }\end{array}$}} & & \multirow[t]{3}{*}{$\begin{array}{l}\text { generalization of other people } \\
\text { Insult without reasons }\end{array}$} \\
\hline Complete cultural competence & 3 & & & & \\
\hline $\begin{array}{c}\text { Show neither cultural } \\
\text { competence nor incompetence }\end{array}$ & 1 & & & & \\
\hline
\end{tabular}

As illustrated by Tab. 1, out of the top ten liked comments, $50 \%$ exhibits either complete cultural competence or display more elements encompassed by the code of cultural competence than not; $60 \%$ displays complete cultural competence, without any expression of cultural incompetence; $40 \%$ presents a higher degree of cultural incompetence with half of which showing a total lack of cultural competence; $10 \%$ barely comments on the technical practicability of the movie.

All prominent expressions of cultural competence seen in the comments gathered were organized and listed. Without any specific order, the first is interpreting the feel-good themed national pride and respect for one's own country as a common sentiment shared by all people of all nations, which directly forms comparison with the reviews with hatred towards Chinese nationalism as presented in the film. Secondly, many evince an appreciation for the casting of black protagonists, indicating the valuing diversity aspect of cultural competence. Thirdly, some reviews imply respect for the Chinese patriotism depicted in the film despite having no personal interest in such an idea. This phenomenon constitutes a notable aspect of cultural competence as it shows both an open attitude, understanding and acknowledgment of differences, and also respect for ideas not preferable or contradictory to yours. Besides, it also forms visible differences with the characteristics seen in the cultural incompetence comments, such as the unwillingness to accept other views, unreasonable insults, and disrespect towards others' opinions. Criticisms for the lack of cultural competence in the film as the actors refer to Africans as natives are recorded as well. Last but not least, commentators would acknowledge and appreciate the production quality of the Chinese movie.

\subsubsection{NE ZHA}

As a traditional Chinese film, Ne Zha seeks to improve international dialogue, targeting its potential audience at adults and children around the world. The era of big data provides technical support for conducting audience surveys, which helps producers explore the further integration of the animation on the market. Besides, the movie Ne Zha acts as a crucial representation of Chinese culture going out on a global stage in cross-cultural communication. Under the language environment of globalization, it also broke many movie records. For example, according to Cartoon Brew, an animation news website, in New Zealand and Australia, the box office records of Chinese films have been set in the past ten years, and the box office records of Chinese films have become the highest in the history of the global film industry.[7] $\mathrm{Ne}$ Zha sets a new benchmark for the creation of domestic animation films and has achieved a double harvest of box office and artistic value. As of early February, Ne Zha had a freshness rating of 87 percent and a popcorn index of 98 percent on Rotten Tomatoes and an IMDb score of 7.7, making it the highest-scoring domestic animation in IMDb, as shown on its official website, in recent years.

Ne Zha is, in fact, a cartoon adapted from Chinese traditional folktales. Since it is told from a Chinese perspective, the movie is an excellent way for people to learn more about Chinese people and culture. For example, Ne Zha uses Chinese kung fu to kill devils for the people; he kicks the shuttlecock as a traditional activity with his mother. Some Chinese-style architectures and landscape paintings are also present in the movie as representations of the profundity of Chinese history and its cultural prosperity.

Despite featuring many traditional Chinese activities, $\mathrm{Ne}$ Zha shows more cultural competence than Wolf Warrior 2 does. The distinction is more apparent when its growth of cultural competence is analyzed in contrast to the folktale of Ne Zha.

In the original $\mathrm{Ne}$ Zha folktale, there is a major conflict between Nezha and his father. However, the movie dilutes the conflict in the original work and adapts it into the double-core growth story of Nezha and Aoki. Thus, the ethical tragedy between a father and a son in the archetype of Chinese classical mythology is transformed into a western-style subjectivity structure of "I can control my life by myself." In addition, the subjective construction of the characters changes as Zha is no longer solitary, as shown in the original story, but, instead, is contained in the care of parental love. At the end of the movie, Nezha even befriends his enemy. The idea reflected in $\mathrm{Ne} Z \mathrm{Zha}$ that "you control your own destiny and decide your own future" makes sense from the perspective of any child's growth. The Li Jing couple becomes a pair of openminded parents, which cast significant influences on the growth of children. These settings are more in line with mainstream international values; therefore, "the devil of Nezha came into the world" is readily accepted by domestic and overseas audiences. In the new movie, the director also merges scientific and technological elements developed in contemporary society, which, to a large extent, shows Chinese growing cultural competence. For example, the fairy unlocks the treasure box containing the 
treasures with his fingerprint, a novel idea prevailing in our daily life currently.

Noticeably, these elements are ones that people all over the world recognize. The change of plot combined with widely-held values shows a high degree of Chinese cultural competence.

The integrated development of Chinese martial arts and animation films has opened up a new path for the external communication of martial arts. The theme or element of martial arts has enriched the field of drawing materials for the creation of animation films, while animation has enriched the diverse media expression of Chinese martial arts. At an operational level, the strategy of sino-foreign cooperation is conducive to cross-cultural communication. At a narrative level, the creation of martial arts animation should seek common themes and narrative strategies based on the domestic mainstream values to gain the recognition of other cultures. At the audience level, this animation film targets not only young audience groups but also the inheritance of Chinese martial arts, which is of great significance for the external communication of Chinese martial arts culture.

The top ten comments for Ne Zha (2019) reorganized according to the code of cultural competence is shown below in Table 2 .

Table 2. Degree of Cultural Competence in Foreign Commentaries of Ne Zha

\begin{tabular}{|c|c|c|c|}
\hline & Number of comments & $\begin{array}{l}\text { Elements of cultural } \\
\text { competence }\end{array}$ & $\begin{array}{l}\text { Elements of cultural } \\
\text { incompetence }\end{array}$ \\
\hline $\begin{array}{l}\text { Complete cultural } \\
\text { incompetence }\end{array}$ & 3 & \multirow{5}{*}{$\begin{array}{l}\text { 1. Praise for Chinese culture } \\
\text { 2. Ability to point out } \\
\text { differences and similarities } \\
\text { between cultures } \\
\text { 3. Respectful of culture despite } \\
\text { not agreeing with the view } \\
\text { fully }\end{array}$} & \multirow{5}{*}{$\begin{array}{l}\text { 1. Unwilling to seek more } \\
\text { information regarding a } \\
\text { new culture } \\
\text { 2. Judge other culture } \\
\text { from that of one's own } \\
\text { 3. Disrespectful of other } \\
\text { views }\end{array}$} \\
\hline $\begin{array}{l}\text { Show more cultural } \\
\text { incompetence }\end{array}$ & 1 & & \\
\hline $\begin{array}{l}\text { Show more cultural } \\
\text { competence }\end{array}$ & 0 & & \\
\hline $\begin{array}{l}\text { Complete cultural } \\
\text { competence }\end{array}$ & 4 & & \\
\hline $\begin{array}{l}\text { Show neither cultural } \\
\text { competence nor } \\
\text { incompetence }\end{array}$ & 2 & & \\
\hline
\end{tabular}

The reviews with more elements of cultural competence and the ones with more cultural incompetence have a ratio of one to one, while each occupying $40 \%$ of all comments. However, all of the commentaries showing cultural competence show no signs of cultural incompetence while the contrary has three-fourth showing complete lack of cultural competence. $20 \%$ of the comments focus solely on criticism of technical perspectives -- an increase in the percentage of commentaries targeting the quality of the film other than cultural elements reveals the difference between an animation movie and the nationalistic action film Wolf Warrior 2 as discussed above.

The common aspects shown in the reviews with the comments adhering to the code of cultural competence include praise for the usage of music performed with Chinese instruments, the depictions of traditional Chinese architecture, and the original ancient myth of Ne Zha, all of which are representative of the Chinese culture, indicating the willingness to interact with another culture. On the contrary, the other $40 \%$ of commentators display an unwillingness to seek more information regarding the Chinese culture and tend to judge the movie from the perspective of his or her cultures with inadequate perceptions. Some reviews also possess the ability to point out differences and similarities between cultures, acknowledging the fact that specific senses of humor, character backstories, and plot points are best interpreted only with knowledge of the Chinese culture, which signals both an understanding of one's own culture and the desire to seek information about another culture. Another expression is respectful of the Chinese culture shown in the movie despite not entirely agreeing with the view, corresponding to the same element shown in Wolf Warrior 2. On the other hand, similar to the features of the lack of cultural competence in Wolf Warrior 2, many commentaries also illustrate disrespect for their opposing opinions. This connection put the issue of respect as the main barrier to cultural competence.

\subsubsection{THE WANDERING EARTH (2019)}

The Wandering Earth, adapted from an original novel written by one of the most famous Chinese science fiction writers, won third place in the Chinese overall box office. It is also widely praised by Chinese film critics as a milestone in Chinese Science fiction movie history. However, according to the collected data, the feedback on this movie from China and abroad varies. The most intuitive number is the domestic and foreign box office performance. The box revenue from the international market only accounts for $0.5 \%$ of the film's global total, and the rating on IMDb is only 6.0 out of 10 while having a 7.9 on Douban, the largest Chinese movie website. Several reasons are accounting for that.

The story happens in 2061 when the Sun is rapidly aging and failing. Under such circumstances, the Earth can no longer rotate regularly and support human living. All nations of the world gather and form the United Earth Government to initiate a project aiming to send the planet 
Earth out of the solar system to the orbit of a star 4.5 lightyears away [8]. Cultural competence is first shown through some details in many scenes. There are mahjong, dragon dancing, and the poster of Bruce Lee. Another interesting plot is the Spring Festival's 12-gun salute, which is shot from one of the planetary thrusters, serving as a giant firecracker to celebrate the Chinese New Year. This creative plot combines traditional customs with an innovative future background setting. It indicates that Chinese people still feel strongly attached to their culture under the despairing "wandering" era.

The whole story happens on the first day of the Chinese New Year. Towards the end of the movie, when the Earth and human civilization are about to end, the protagonist persuades the United Earth Government with his speech about the Chinese new year. On the first day of the Chinese new year, families are supposed to reunite together. But now, for future generations, the protagonist decides to sacrifice his own family to save all of humanity. The French official of the United Earth Government in the movie understands the importance of this day for Chinese and the great sacrifice the protagonist is going to make. The official eventually decides to help him and appeals to people all around the world to not give up hope, showing the acknowledgment of the other worldview coming from a different culture.

Besides, when the Russain in the film says, "you can't know more about space than I do. We Russians invented the space station 100 years ago," the camera gives one little mark stating "made in China" on the hatch a shot. This plot not only admits Russian strength in aerospace engineering but also modestly implies that the Chinese manufacturing industry has developed exceedingly. This small but intriguing detail functions as a friendly expression based on mutual understanding, showing an ability to openly discuss differences between one's own culture and another.

Ultimately, according to the director, Fan Guo, home is not just a physical space for Chinese people: "the Earth is not just a physical object when we push it away from the orbit of the Sun in this film. We are pushing away our

Table 3. Degree of Cultural Competence in Foreign Commentaries of The Wandering Earth

\begin{tabular}{|c|c|c|c|}
\hline & Number of comments & $\begin{array}{l}\text { Elements of cultural } \\
\text { competence }\end{array}$ & $\begin{array}{l}\text { Elements of cultural } \\
\text { incompetence }\end{array}$ \\
\hline $\begin{array}{l}\text { Complete cultural } \\
\text { incompetence }\end{array}$ & 1 & \multirow{5}{*}{$\begin{array}{l}\text { 1. Praise for Chinese CG } \\
\text { effects } \\
\text { 2. Chinese specialty } \\
\text { 3. Praise Chinese culture: no } \\
\text { individualism } \\
\text { 4. Understanding a common } \\
\text { sentiment }\end{array}$} & \multirow{5}{*}{$\begin{array}{l}\text { 1. Dislike nationalism } \\
\text { 2. Regard this movie as an } \\
\text { imitation of Hollywood } \\
\text { movies } \\
\text { 3. The characters are } \\
\text { cardboard cutouts and } \\
\text { virtually every element is } \\
\text { derivative of American } \\
\text { blockbusters. } \\
\text { 4. Chinese movies are } \\
\text { cliche and cringe-worthy. }\end{array}$} \\
\hline $\begin{array}{l}\text { Show more cultural } \\
\text { incompetence }\end{array}$ & 3 & & \\
\hline $\begin{array}{l}\text { Show more cultural } \\
\text { competence }\end{array}$ & 2 & & \\
\hline $\begin{array}{l}\text { Complete cultural } \\
\text { competence }\end{array}$ & 2 & & \\
\hline $\begin{array}{l}\text { Show neither cultural } \\
\text { competence nor } \\
\text { incompetence }\end{array}$ & 2 & & \\
\hline
\end{tabular}

The reviews with more elements of cultural competence

and the ones with more cultural incompetence have a ratio home, the reservoir of our emotions." This unique emotion of home is not a western concept, but rather only belongs to Chinese culture. The way that Chinese people understand the concept of "home" makes this film a real Sci-fi from the inside. And for foreigners, the entire plot is unusual. And this is precisely the core of this Chinese science fiction film.[9]

Nostalgic provincialism is a unique complex meaning "being attached to one's native land and unwilling to leave it" developed through Chinese long strife and unification history. Ancient Chinese have long been suffering from displacement because of endless regional splits, and thus have developed a strong sense of belonging to their home and homeland. As a result, the decision to abandon "home" and fight for survival at any cost means much more to Chinese people than shown on the surface. The concept of nostalgic provincialism is also redefined in this film. It no longer only represents one's unwillingness to leave home, but that home is where the people are. The galaxy our physical shelter belongs to does not matter, which is the reason why people on Earth eventually choose to bring the whole Earth to another galaxy instead of migrating with spaceships. It shows not only an understanding of one's own culture but also an openness to change in ideas of one's own culture.

Apart from that, the director clearly expressed that this film is not for the international market. He thinks that we are not yet able to make films from a global perspective, and Chinese culture is yet to be understood fully across the globe.[10] Language and cultural barriers prevent it from being broadly accepted by international audiences. However, this film is now available on Netflix and has also received decent reviews from many international audiences. All because of the high-quality works in the entertainment industry, people around the world are showing more and more mutual respect and appreciation for the different cultures from another worldview.

The top ten comments for The Wandering Earth (2019) reorganized according to the code of cultural competence is shown below in Table 3 . of 3 to 2, occupying $50 \%$ of all comments together. Only one comment shows cultural incompetence, and the other 
two show to some extent of cultural incompetence. The groups of comments showing cultural competence share some common aspects: the three displaying more cultural competence all praise the Chinese CG effects in the movie; two of them also regard this film as a Chinese specialty. One remark applauds this film for demonstrating the core of Chinese spirit: collectivism instead of individualism. From these aspects of cultural competence, these film reviewers possess a deeper understanding of Chinese culture. While presenting strong appreciation and acceptance of Chinese culture, these reviews tend to praise the film more and regard it as a milestone in Chinese scientific movie history.

As for the two reviews displaying more cultural incompetence, they grade much lower than those showing more cultural competence. These reviews reveal strong sentiments against this film as well as Chinese culture. Both of them dislike the nationalism presented in this film, holding the opinion that as scientific film, the promotion of communism should not be allowed. Besides, these two reviews regard this film as an imitation of Hollywood blockbusters. They point out that the characters are cardboard cutouts and virtually every element is derivative of American blockbusters. One of them concludes that The Wandering Earth is a remake of a Hollywood film and the other claims that Chinese movies are cliche and cringeworthy.

Excellent CG effect, catastrophe, and saving the earth, this film does have many similarities with Hollywood's successful film productions. However, having a sense of cultural competence could possibly help one understand this movie better.

\section{DISCUSSION}

As conveyed by our data above, change in the Chinese cultural competence level reveals an overall decreasing trend with an escalating amount of disrespectful insults and waning confidence and appreciation for one's own culture. This statistic supports that after exposure to Western media response, Chinese Weibo netizens tend to become less rational and, consequently, less culturally competent.

However, the event surrounding Zhang WeiLi, one out of the six cases selected, demonstrates a decrease in the number of insults and mockeries accompanied by a startling increase in rational arguments and criticisms, both signifying growth in cultural competence. We suspect the nature of the event affects the result. Further investigation of the causes of such statistical differences would be beneficial in identifying barriers and, consequently, developing strategies to overcome them in achieving cultural competence. The analysis of the language used by the media reporting the Western response to the event of Zhang WeiLi's victory pinpoints a clear presentation of respect and appreciation for Chinese. Zhang WeiLi's case manifests the significance of the presence of respect in conversations to help improve cultural competence.
Our analysis of movies discovered a slight majority of comments showing cultural competence with the three highest-grossing films in China, all of which exhibiting both Chinese culture and elements of cultural competence. From the remarks containing culturally competent components, the following primary reasonings behind the phenomenon were deducted:

1. Being knowledgeable in the field of discussion, in this case, the entertainment industries with other films of the same genre and actors

2. Having an understanding of similarities among all people of all countries

3. Past experiences or being knowledgeable with the culture of contact, including direct help with translation form a subject of the other culture

4. Interest in another culture

All the above requirements are believed to be fulfilled by the film industry. As demonstrated by Wolf Warrior 2 (2017), Ne Zha (2019), and The Wandering Earth (2019), the deeper the level of cultural competence is shown in a film, the more accepting the foreign audience would be in admitting and reapplying the same depth of cultural competence. Similarly, the same applies to the situation in China.

Common barriers to achieving complete cultural competence include the difference in language, diminishing interest one may have in learning about another culture, and the fundamental disparities in traditions that directors often fail to address and explain. Although overcoming the language inconsistency may seem impossible, through translating with the knowledge of the other culture in mind, the quality of translation could be improved tremendously, getting the humor and shortcuts in conversations right for the new group of distinct non-native audience. The simplest solution to increase understanding and knowledge of one's own culture would be to add in the plot a section explaining the basics of the traditions of the culture. While this may not eliminate all possibility of cultural incompetence, it would create an atmosphere of mutual understanding between the filmmaker and the audiences from various cultures.

Although the reception of Western opinions during the pandemic spurred a decline in the degree of cultural competence, a reversed trend is achievable through the involvement of more informative and unbiased films about the other culture, the Western culture.

\section{CONCLUSION}

The paper was established by the problem of the predominance of cultural incompetence during the COVID-19 pandemic. While previous research on cultural competence applied to areas in healthcare, referring to the ability of healthcare professionals to interact with patients having different values, beliefs, and emotions, our study provides a distinguished outlook into a new field. With a code of cultural competence developed through operationalization, comments underneath Western posts of Chinese events were utilized for analysis of Chinese 
behavior towards those comments and Chinese netizens' reactions to those foreign posts. Data collected on six selected events reveal a continuously decreasing trend in Chinese netizens' level of cultural competence.

Through analysis of the first three top-grossing Chinese movies and examination of the elements shown in these movies, a strong positive association was found to exist between films possessing cross-cultural aspects and the degrees of cultural competence of people. Entertainment, especially films, proved to be a causal factor for increasing the possibility space and growth in establishments of compelling cross-cultural understandings and communication, both essential to the process of cultural competence growth.

The investigation in the unique case of Zhang WeiLi pinpoints respect as an influential factor of high cultural competence status. Characteristics and qualities similar to such can be explored in future studies.

Admittedly, our research contains limitations. First, the population accounted for was limited. Future research in this area should consider operating with a greater sample size for more specific and accurate results. The popularity of each comment included, although not entirely accountable for the deficiency in the number of samples, helps establish a credible research result. Second, the number of movies chosen was confined. Through broader analysis, more connections are discernible between movies and cultural competence, as well as specific elements of films contributing to a higher level of competence.

Nevertheless, our study provides an overview and initiates a connection between Chinese netizens' cultural incompetence and western posts published during COVID19. Our demonstration of the effectiveness of movies in reinforcing the concept of cultural competence provides a direction for later development of future film industries. Films, as the mainstream of mass media, carrying more cultural competence related components and boosting such exposures to the audience would be regarded as an overall advancement of our shared society. Our new understanding of cultural competence refers to the intercultural ability for people within different cultures to accept and interact with other cultures. Our application of the concept has shifted the previous healthcare-oriented reinforcement into a cultural, civic, and political domain. We would like to thank Dr.Francis Steen for his professional advice and assistance that greatly facilitated the research process.

\section{REFERENCES}

[1] Curricula Enhancement Module Series. (n.d.). Retrieved from https://nccc.georgetown.edu/curricula/culturalcompeten ce.html

[2] Pandey, S. (2012). Using popular movies in teaching cross-cultural management. European Journal of Training and Development, Vol. 36 No. 2/3, 329-350.
Retrieved May 15, 2020, from https://doi.org/10.1108/03090591211204779

[3] Cultural Competence. (n.d.). Retrieved May 10, 2020, from

https://cdn.ymaws.com/www.naswaz.com/resource/res mgr/imported/CulturalCompetence.pdf

[4] Irving, L., \& Moreno, J. (n.d.). What is Cultural Competence. Retrieved May 18, 2020, from https://www.umaryland.edu/media/son/faculty-staff/What-is-Cultural-Competence.pdf

[5] Movies' Box Office Ranking. (n.d.). Retrieved April 29, 2020, from http://58921.com/alltime

[6] Reduan64. (2017). 2017 - Wolf Warrior 2.

Retrieved May 04, 2020, from http://kayling88ent.blogspot.com/2018/02/2017-wolfwarrior-2.html

[7] Wit, A. (2019, August 02). 'Nezha' Overtakes 'Zootopia,' Sets All-Time Highest-Grossing Chinese Animation Record. Retrieved May 07, 2020, from https://www.cartoonbrew.com/box-office-report/nezhaovertakes-zootopia-sets-all-time-highest-grossingchinese-animation-record-177757.html

[8] The Wandering Earth. (2019, February 05). Retrieved May 08, 2020, from https://www.imdb.com/title/tt7605074/?ref_=tturv_ql

[9] Gao, X. (2019). Director of "The Wandering Earth" Spoke About His Audience Being All Chinese.

Retrieved May 15, 2020, from https://www.guancha.cn/politics/2019_02_12_489811.s html

[10] Angela J Ballantyne, E. (2017, March 1). Patient participation in clinical ethics support services Patient-centered care, justice and cultural competence Angela J Ballantyne, Elizabeth Dai, Ben Gray, 2017. Retrieved May 08, 2020, from https://journals.sagepub.com/doi/10.1177/14777509166 61976 